object of class room presentation and discussion at a large number of summer schools throughout the country this summer. Indeed some of the most prominent institutions have built the work in mathematics intended for the preparation of teachers around the various preliminary reports of the National Committee.

Professor E. R. Hedrick, of the University of Missouri, lectured before a number of institutions on behalf of the National Committee from June 20 to August 9. The institutions visited were: The University of Texas; The University of Oklahoma; The University of Nebraska; The State Normal Schools at Peru and Kearney, Nebraska; The University of Chicago; The University of Iowa; Iowa State Teachers College; The University of Michigan; Northwestern University. Professor Hedrick was enthusiastically received at all of these institutions.

\title{
ARE COLLEGE GRADUATES IN CHEMISTRY FITTED TO TAKE UP RESEARCH PROBLEMS? IF NOT, WHY NOT?
}

BY H. D. GIBBS.

My experience in Universities, in Government and in Industrial Research Laboratories leads me to answer the first question in the negative. A graduate of a four-year course, as ordinarily arranged for specialization in chemistry, is seldom fitted for research, and a Doctor of Philosophy with seven years of Uni versity study behind him, is often woefully lacking.

This deficiency, in my opinion, may be attributed to several causes.

I would put first, the small percentage of graduates who have the making in their fibre of real research men. For the past few years chemistry has been the most advertised of the sciences and therefore on account of the great war activities and the salaries that industries offered to pay, not only to the best but also to men of mediocre ability, many have flocked to the University lecture rooms and laboratories when it would have been more advantageous both to themselves and to the advancement of chemistry had they chosen another profession or training for their life work. We are now facing an over production of so-called chemists. I do not believe this country will be saturated in the near future with an adequate number of real chemists, but the difficulty at the present is the winnowing of the wheat from the chaff. To a certain extent both are suffering, due to that portion of the cycle, both business and educational, in which we are now operating.

We have always in course of production in educational institutions and even in research laboratories attached to industries, a small percentage of men who will be research chemists of the highest grade, not primarily due to the surrounding conditions, but in spite of them, given the proper environment in educational facilities, inspiration both from teachers, directors and associates, this number is greatly increased.

A second cause may be placed as lack of proper educational facilities and inspiration. By proper educational facilities I do not refer so much to well equipped laboratories and lecture rooms, that is the plant, as I do the the courses of study and the methods of presenting them.

The best research men do not have their minds crowded with facts, figures and reactions, but they do have fundamental principles and methods of working and have acquired skill in handling apparatus, manipulations and careful and complete observations. A general knowledge of the literature has been acquired so that complete data of any specific subject can be found with facility.

Without the proper inspiration from superiors, associates and surroundings good research is almost impossible. For these reasons many of our industrial laboratories are, at the present time, poor places to develop and foster research. 


\title{
Thewanneer \\ LABORATORY FURNITURE
}

\author{
for the teaching of
}

\section{Physics \\ Biology \\ Electricity \\ Chemistry \\ Zoology \\ Physiography}

Superintendents and Instructors will be interested in Kewaunee designs, embodying, as they do, the co-ordinated results of your experience in teaching, and ours in manufacturing. Better Laboratory Equipment is absolutely essential to thorough work on the part of the instructor and intelligent reciprocation on the part of the student.

We have many letters from Boards of Education and Science Instructors testifying to the merit of Kewaunee Equipment.

Geo. A. McFarland, Supt. of Dept. of Education, Williston, N. D. writes:

"The Chemistry Desks and Biological Tables ze purchased from you have given entire satisfastion. They are substantial, complete and convenient."

Educational Executives who are considering installation of new equipment should have a copy of the Kewaunee Book. Just ask for it.

For complete information address the factory at Kewaunee.

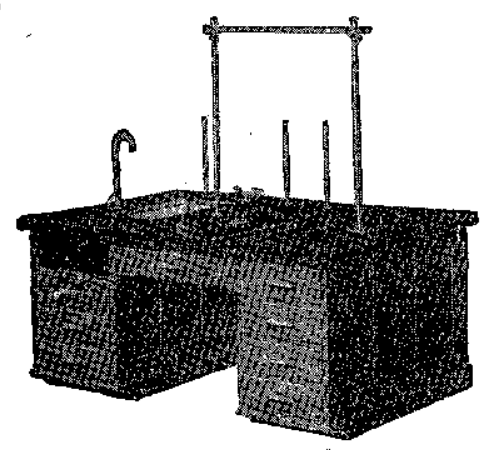

Instructor's Desk No. 1401. Suited to the Physics or Chemistry Laboratory or the Leeture Room. Especially designed for smaller schools.

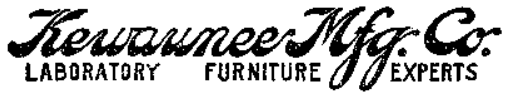

114. Lincoln Street, KEWAUNEE, WIS.

New York Office 70 Fifth Avenue

Canadian Sales Division 615 Yonge St., Toronto, Canada BRANCH OFFICES:

CHICAGo. MINNEAPOLIS KANSAS CrTY ATLANTA ALEXANDRIa, LA. PHOENIX COLUMBUS HOUSTON LITTLE ROCK LOS ANGELES DENVER SPOKANE OKLAHOMA CITY JACKSON, MISS. 